\title{
The use of controlling-training software in civil engineering bachelors' educational process
}

\author{
Sergey Rekunov ${ }^{1, *}$, Galina Voronkova ${ }^{1}$, and Maria Doskovskaya ${ }^{2}$ \\ ${ }^{1}$ Volgograd State Technical University, Institute of Architecture and Civil Engineering, 1, \\ Akademicheskaya St., 400074, Volgograd, Russian Federation \\ ${ }^{2}$ Samara State Technical University, Institute of Architecture and Civil Engineering, 194 \\ Molodogvardeyskaya St., 443001, Samara, Russian Federation
}

\begin{abstract}
The paper considers the current state of the higher education system of the Russian Federation in the context of teaching disciplines of strength cycle with the use of information educational technologies. The educational process in the discipline "Structural Mechanics" is shown by using the Controlling-Training Software on the sample program "Statically Determinate Plane Truss". Such software was developed by employees of the Department of Structural Mechanics of the Institute of Architecture and Civil Engineering of Volgograd State Technical University to heighten student's interest in calculations of building structures while using computer-based teaching methods, as well as to simplify the existing monitoring procedure. The Controlling-Training Software makes it possible not only to consolidate but also to independently assess the acquired theoretical knowledge. Working with this program displays all necessary information: the calculated scheme, the area of issues, an area with a commentary on the input response. Help files contain a sufficient amount of theoretical material with examples of solutions. Students have several attempts to enter their answer. If they are unsuccessful, then the screen displays the correct answer with visual graphic illustration and explanation of this issue. Carrying out the educational process by use of the Controlling-Training Software resulted in saving a significant amount of academic time.
\end{abstract}

\section{Introduction}

The introduction of the multilevel system in the Russian education has led to a significant change in the structure, content and technologies of the educational process and all educational programs of students' assessment. The use of the Credits became the reason of sharp decrease in number of academic hours in many disciplines, which are not required in accordance with the requirements of State Educational Standards.

In the modern Standards requirements for mandatory implementation of active and interactive forms of education in the educational process are introduced. Their share must

\footnotetext{
*Corresponding author: rekunoff@mail.ru
} 
be at least $20 \%$ of the classroom teaching. Under these conditions, no alternative is given for the mandatory use of modern information technologies in educational process.

\section{Materials and Methods}

The main elements of the educational process in special disciplines of engineering are lectures and practical classes. The basic disciplines for the training of would-be civil engineers are "Theoretical Mechanics", "Engineering Mechanics", "Strength of Materials" and "Structural Mechanics".

Interactive forms of learning in these disciplines are used in the e-learning courses, which include theoretical material and training software. Theoretical material helps students with the basics of the discipline (electronic lectures, methodical and normative literature). Controlling-Training Software allows not only to consolidate but also to assess independently the acquired theoretical knowledge [1-9].

Placement on the website of the University like e-learning courses of disciplines in advance of the training on this discipline will allow the student to form an idea about the course and assess their level of material acquisition.

In turn, the tutor who uses these courses can minimize the amount of classroom time devoted to compulsory presentation of the theoretical foundations and pay much more attention to their practical application [10-13].

\section{Results}

During several years the Department of Structural Mechanics of the Institute of Architecture and Civil Engineering of Volgograd State Technical University has developed and actively applied Controlling-Training software for the academic discipline "Structural Mechanics". For each section of an educational discipline the members of the Department developed relevant programs (software). The successful use of our software in the educational process is based on the increased interest of students in computer training techniques compared to conventional methods. Application of user-friendly visual imagery and interactive tips allows to greatly simplify the process of theoretical material perception and to promote calculations of building structures by methods of structural mechanics.

All programs are made in the same style (color, font, graphics, etc.) with common interface elements [14-17]. Next, we consider the main elements of the program on the example software "Statically Determinate Plane Truss". 


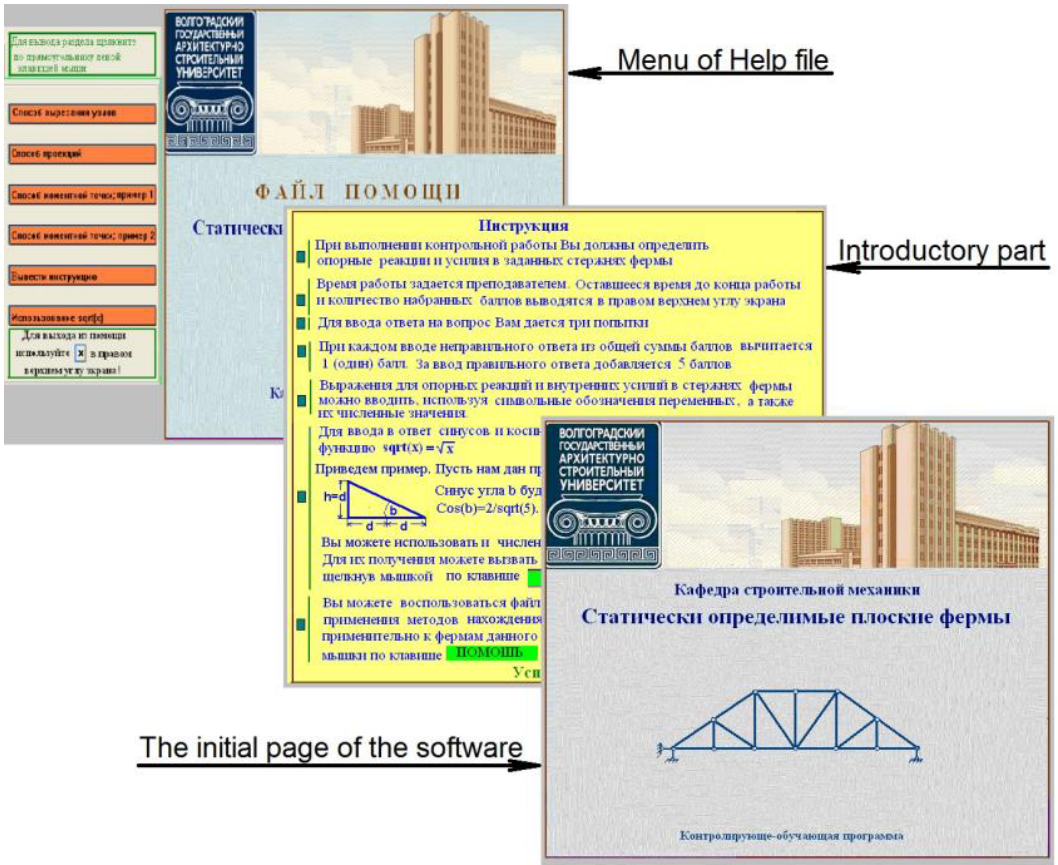

Fig. 1. Interface of the software "Statically Determinate Plane Truss".

At the beginning of the program the guide is placed. It explains the objectives of control work, the system of evaluating the task, the basic provisions and explanations for carrying out the work (Fig. 1).

At any time of the control work it is possible to use the Help file which contains a sufficient amount of theoretical material with examples of solutions.

Further follows a page where the student enters his data (initials and the group number), then appears variants of tasks (Fig. 2). Variant number of the task is entered by the teacher.

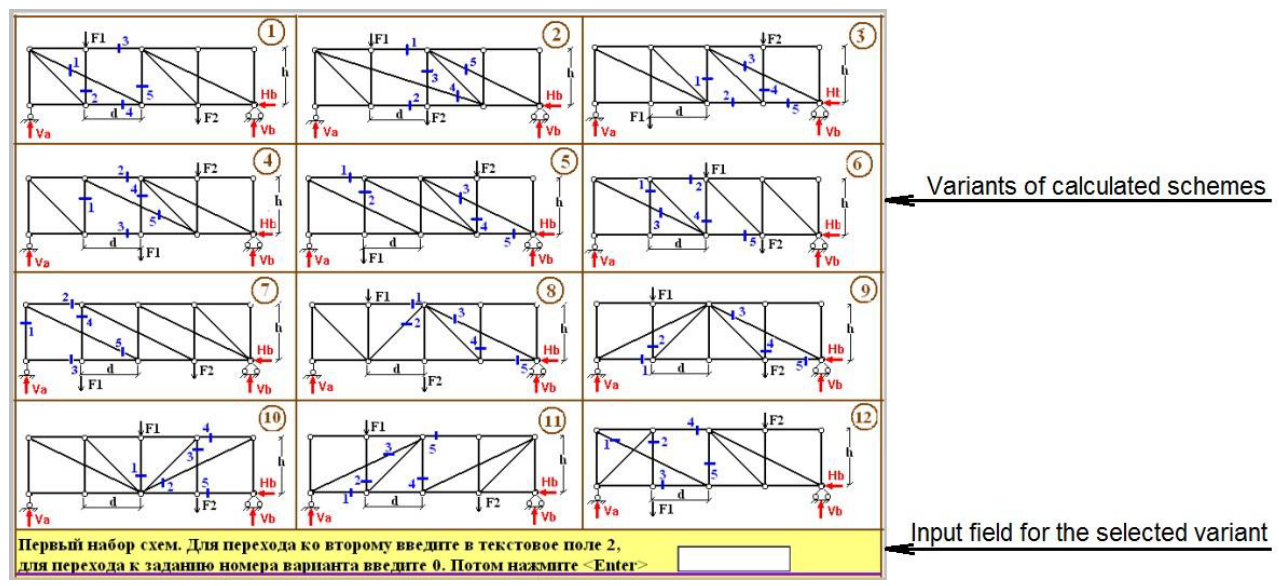

Fig. 2. Page with variants of calculated schemes

The next page is given to formulation of the problem and the numerical values of set parameters. Also, there is a field for an internal stresses, which are necessary to determine, an area for input of the answers, help button and a calculator. At the top of the screen is 
displayed the current status line, which shows the data of the student, the number of their scored points and time remaining until the end of the implementation of control work (Fig. $3)$.

Student independently carries out a choice of the unknown to determine support reaction or internal stress. When writing an answer is possible to use the symbolic name of the given parameters and have already defined variables or their numerical values.

To enter any answer the student has several attempts. If they are unsuccessful, then the screen displays the correct answer with visual graphic illustration and explanation on this issue. With the right answer the required stress is colored green. If the answer is wrong the required stress is colored red (Fig. 4).

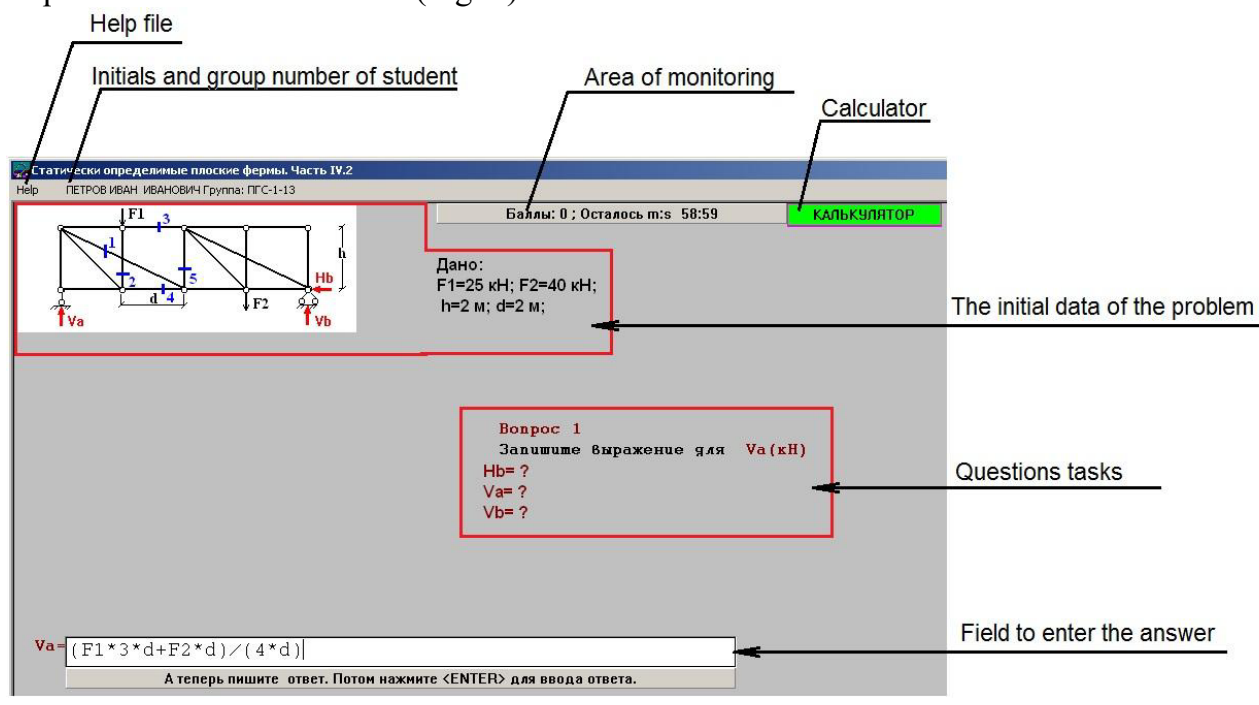

Fig. 3. Workspace of the Controlling-Training software.

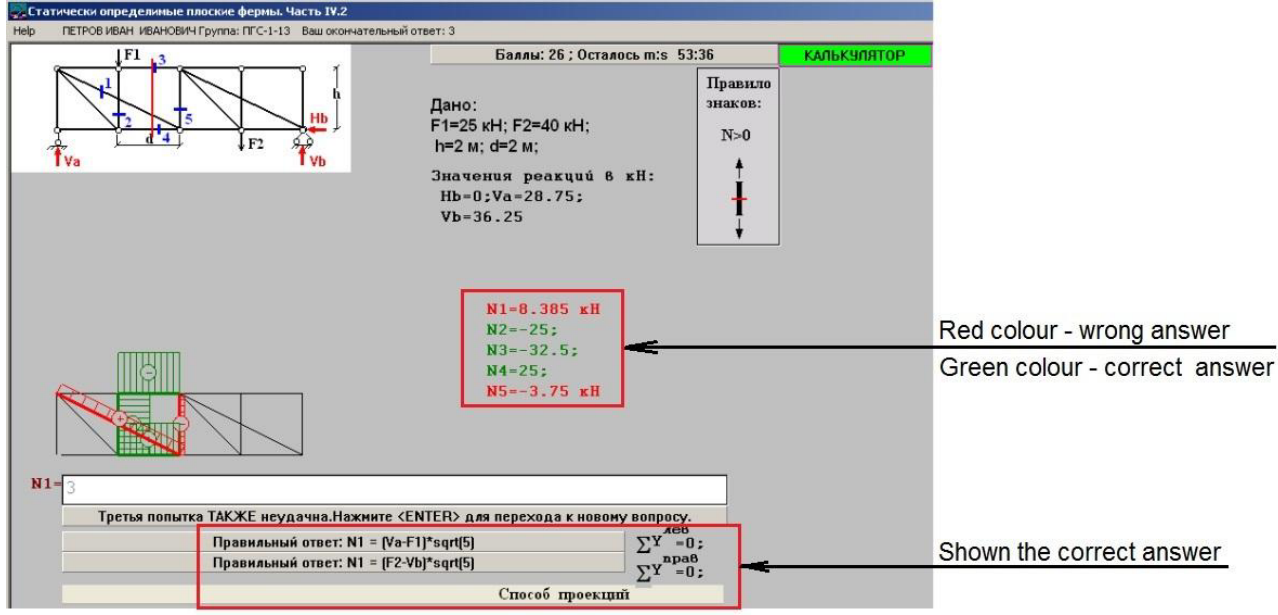

Fig. 4. Data entry.

After completing the control work, students automatically receive a score depending on the number of points. The total score is displayed on screen and also recorded in the statistics file. 


\section{Discussion}

The main feature of disciplines of strength cycle is ability to solve a large number of tasks, without which further development of the educational program is not possible. Therefore, the reduction of such an important component of the educational process as independent calculations is not valid.

The application of the Controlling-Training Software in the period of examination sessions for students of correspondence courses has shown high efficiency and helps significantly reduce the time taken for check of the test works. Also it facilitates to avoid disputable issues in matters of objective evaluation of the results.

Three stages of tests were done to find and eliminate defects in the program. In the first stage, the program was tested by a group of specialists in the field of structural mechanics to detect errors in solving test problems, i.e. digital and character misprints, correctness in using formulas, etc.

In the second stage, the program was tested by a group of students who have already studied the topic. This helped to add new subsections to the program interface, Help in particular.

In the third stage of testing, the program was tested by a group of students who just started to learn this course. All comments were later taken into account by the developers of the program.

\section{Conclusions}

Carrying out the current control of educational process by making control works in the Controlling-Training Software with the interactive graphical prompts and objective computer evaluation of the results of this decision resulted in a saving of more than $50 \%$ of academic hours, and possibly increased academic progress of students by $15 \%$ compared with traditional forms of teaching.

\section{References}

1. S. S. Rekunov, Internet magazine «Naukovedenie» 3 (16) Access: http://naukovedenie.ru (2013)

2. S. S. Rekunov, The use of innovative technologies to address agro-industrial complex in modern conditions, International scientific-practical conference dedicated to the 65th anniversary of the Volgograd State Agricultural Academy, 3, 30-32 (2009).

3. I. G. Ovchinnikov, I. I. Ovchinnikov, Red line. Road. Innovations in road construction 47. p. 26-27 (2010).

4. B. E. Skurikhina, O. A. Kochukov, Architecture. Construction. Education 2 (6), 207$212(2015)$.

5. N. V. Kupchikova, L. Yu. Bobrova, Perspectives of development of construction complex 2. p. 121-124 (2012).

6. O. A. Ganzha, O G. Kulik, N. A. Rogozin, O. V. Chmak. Quality management in higher education (2014)

7. G. V. Voronkova, S. Yu. Katerinina, Problems of implementation of results of innovative development, International scientific-practical conference 2, 24-26 (2016).

8. S.V. Nikiforova, V.N. Mikhelkevich, Science Vector of Toglyatti State University 1 (23), 353-356 (2013)

9. M. I. Balzannikov, S.Ya.Galitskov, A.G.Chiknovoryan, Development of Higher Education in Civil Engineering in Russia and other Countries: Materials of 
International Scientific Seminar of «Association of Educational Civil Engineering Institutions», 31-36 (2006)

10. S. Ya. Galitskov, V. N. Mikhelkevich, Traditions and innovations in the construction and architecture, 946-948 (2014)

11. A. S. Bryatov, V. N. Mikhelkevich, V. M. Myakishev, Vestnik of Samara State Technical University: Psychological and Pedagogical Sciences 1, 15-19 (2012)

12. K. S. Galitskov, V. N. Mikhelkevich, Science and Education in Modern Society: Materials of International Conference, 41-44 (2013)

13. O. A. Ganzha, G. V. Voronkova, S. A. Shestakov, O. V. Ignatiev, All-Russia scientificpractical conference proceedings, Volgograd Academy of public service, 68-74 (2008).

14. O. V. Ignatiev, Vestnik VolgGASU, Architecture and civil engineering 6, 24-30 (2007).

15. S. Yu. Katerinina, Yu. I. Uskov, Current research trends of the XXI century: Theory and Practice, 3, 7-4 (18-4), 275-279 (2015).

16. E. V. Ivanova, O. A. Omarov, N. O. Omarova, Scientific notes IIE RAE, 25-31 (2013).

17. E. P. Chernyshova, A. D. Grigoriev, Modern problems of architecture, fine arts and design, All-Russia scientific-practical conference proceedings, 39-49 (2009). 